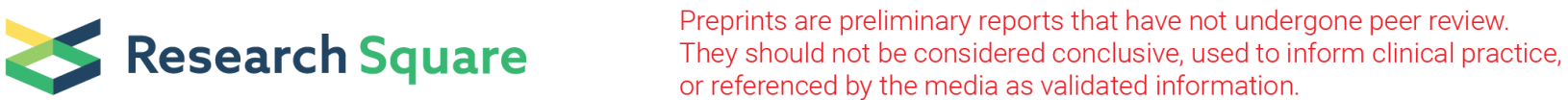 \\ A Case Report Based On Complete Androgen Insensitivity Syndrome
}

\section{pengju li}

Sun Yat-sen University First Affiliated Hospital

jiefei xiao

Sun Yat-sen University First Affiliated Hospital

junhang luo

Sun Yat-sen University First Affiliated Hospital

wei chen ( $\nabla$ chenweiurology@163.com )

Sun Yat-sen University First Affiliated Hospital

Case Report

Keywords: AR gene, complete androgen insensitivity syndrome, case report ,46XY female phenotype

Posted Date: March 12th, 2020

DOI: https://doi.org/10.21203/rs.3.rs-17021/v1

License: (c) (i) This work is licensed under a Creative Commons Attribution 4.0 International License. Read Full License 


\section{Abstract}

Background: Androgen insensitivity syndrome (AIS) is a rare disease caused by mutations in the AR gene. This results in resistance to the actions of androgen as well as a female phenotype with $46 \mathrm{XY}$. Anatomically, individuals with AIS lack both a uterus and ovaries.

Case presentation: In this case report, we detail a 32-year-old patient with complete AIS (CAIS). This female patient with $46 \mathrm{XY}$ genotype came to our hospital seeking surgical removal of bilateral testis. The subsequent medical history, clinical examination, imaging, and endocrine outcomes from this patient were collected and are presented here.

Conclusions: Individuals with CAIS need appropriate care from doctors and support from their family. The diagnosis, treatment, and management of CAIS also requires a multidisciplinary approach.

\section{Background}

Androgen insensitivity syndrome (AIS) is a rare disease caused by defect in the androgen receptor (AR) gene, which is located on the $X$ chromosome (Xq11-q12). ${ }^{1}$ Owing to a complete or partial resistance to the actions of androgen, AIS can be categorized as mild (MAIS), partial (PAIS), or complete (CAIS). The clinical features of this syndrome range from infertility and/or adolescent gynaecomastia with a male phenotype, to inconclusive biological gender, to a female karyotype of $46 \mathrm{XY} .^{2}$ CAIS was previously known as testicular feminization syndrome and was first fully described by John Morris in 1953. In research examining 82 cases, individuals with CAIS presented with a female appearance and normal breast development, absence of uterus and ovaries, bilateral undescended testis, and elevated testosterone levels. ${ }^{3}$ Here, we report a case of CAIS in a 32-year-old woman with cryptorchidism. The patient's clinical and pathological outcomes were collected and are presented here.

\section{Case Presentation}

A 32-year-old woman with cryptorchidism was referred to our urology department at The First Affiliated Hospital of Sun Yat-sen University on January 2, 2019. Figure 1 shows the pedigree of the patient and her family history indicated that three other females across three generations had the same clinical condition as her. The patient reported that she has a bilateral inguinal mass, which she noticed when she was 10 years old. In 2010, an ultrasonography was performed and showed complete absence of the uterus and ovaries. On clinical examination, the patient was $157 \mathrm{~cm}$ in height and $54 \mathrm{~kg}$ in weight. She had normal breast development and normal female external genitalia with thinning of the pubic and axillary hair. Bimanual examination revealed a short, blind vagina. Subsequent to this examination, the patient had bilateral gonadectomy on January 8, 2019. Pre-and post-operative hormone data were collected and are shown in Table 1. Imaging performed prior to the removal of both testes was collected and is shown in Fig. 2a. Cytogenetic analysis revealed a 46 XY karyotype (Fig. 2b). Pathology results of both testes are shown in Fig. 3. 


\section{Discussion And Conclusions}

AIS is a type of disorder of sexual development (DSD). Generally speaking, DSD is caused by a defect in gonadal development, androgen synthesis, and/or the actions of androgen. Given this, AIS is classed as a defect in the actions of androgen. Although the formed testis secrete sufficient amounts of active androgen, a lack of function of the androgen receptor is the main reason for androgen insensitivity in these patients. ${ }^{4}$ Several AIS cases have indicated that mutations of the AR gene are also a feature of this condition..$^{5-9}$ Using genotyping in 41 cases of AIS, Maria Sol Touzon reported that the percent of CAIS patients with an AR mutation was around $100 \%$; comparatively, it was $43.3 \%$ in patients with PAIS. ${ }^{10}$

The AR gene is approximately $90 \mathrm{~kb}$ in size and is located on the $X$ chromosome (Xq11-q12). The gene has eight exons, which encode for a 917 amino acid-long protein.1,4 The AR is a member of the steroidhormone family of receptors, which also includes estrogen, progesterone, and glucocorticoid receptors. The AR contains four functional domains: A large N-terminal domain (NTD) encoded by the largest (1613 base pairs) exon 1, a DNA-binding domain (DBD) encoded by exons 2 and 3 , a hinge domain, and a Cterminal ligand-binding domain (LBD) encoded by exons $5-8$. The $\mathrm{N}$-terminal portion is essential for its receptor activity. The DBD portion contains two zinc finger regions to both bind DNA and activate genetic transcription. The $\mathrm{C}$-terminal ligand-binding domain is the most commonly reported site of androgen receptor mutations. The structure of the AR gene and the AR itself are shown in Fig. 4, as adapted from Wiener JS et al. ${ }^{11}$

AIS is a rare disease and there is no clear data regarding its prevalence. Reported estimates range from $1: 20,400$ to $1: 99,100$ genetic males with CAIS. ${ }^{12}$ AIS is classed into three subtypes: (1) MAIS, which is found in males with persistent gynecomastia and/or infertility; (2) PAIS, which is found in individuals with atypical genitalia, and (3) CAIS, which is found in individuals with a $46 \mathrm{XY}$ female karyotype. The typical presentation for CAIS includes a $46 \mathrm{XY}$ karyotype with a female phenotype, primary amenorrhea in adolescence, and/or an inguinal mass in an infant. 2 In this case, the patient reported that the bilateral Inguinal mass was discovered when she was 10 years old. A female phenotype with $46 \mathrm{XY}$ always has normal breast development, while pubic and axillary hair are usually absent or can be present in sparse amounts. The development of the uterus, cervix, and proximal vagina are suppressed in CAIS, due to the actions of Anti-Mullerian Hormone (AMH) produced by the testes. The vagina varies from a dimple in the perineum to one of normal length, but is always blind-ending.2,6 The clinical examination presented in this case fits this description. Adult women with CAIS are generally taller than women without the syndrome, but are-on average-shorter than the male population. ${ }^{13}$ The case we report here was also similar in this regard. Notably, it has been reported that patients who delay gonadectomy are even taller. ${ }^{14}$

The hormone profile gathered from this case are shown in Table 1. We tested levels of estradiol, folliclestimulating hormone (FSH), luteinizing hormone (LH), PRL, testosterone, and progesterone. sompared with normal males, female with CAIS have normal or above-normal levels of serum testosterone and $\mathrm{LH}$, while FSH levels are not increased. ${ }^{15}$ The reason for this may be that gonadal inhibin regulates FSH 
level. ${ }^{16}$ In a newborn, AIS could be diagnosed because of increased serum AMH and testosterone levels, while gonadal dysgenesis would be excluded. ${ }^{17}$

Bilateral gonadecomy should be performed after diagnose to avoid the risk of malignancies. However, maintenance of the testes could maintain estrogen at a normal level to allow for spontaneous breast development. The risk of malignancies is very low before adolescence, but increases with time. ${ }^{18}$ Given this, the timing of the surgical removal of bilateral testes is very important. Estrogen replacement is necessary after surgery. ${ }^{19}$ Surgical methods to create a vagina should be avoided, because non-surgical methods are cheap, safe, and effective. It should also be mentioned that vaginal angioplasty is not necessary and vaginal dilation promotes an adequate vaginal length. Vaginal dilation should occur after puberty or when the patient wants to initiate sexual activity. ${ }^{20}$

AIS is a rare disease; however, genetic and phenotype gender separation remain problematic in these patients. CAIS presents as an inguinal hernia or labial swelling containing a testis in an apparently female infant. Diagnosing the disease requires genetic analysis. In a recent study, it was reported that analysis of androgen receptor mRNA obtained from whole blood would be a potential strategy for the detection of androgen receptor gene splicing defects. ${ }^{21}$ The time for bilateral gonadecomy is very important and estrogen replacement is necessary. Psychological care from doctors, psychologists, and support from family are absolutely necessary in the procedures required for this condition.

\section{Abbreviations}

AMH Anti-Mullerian Hormone

FSH follicle-stimulating hormone

MAIS mild androgen insensitivity syndrome

NTD N-terminal domain

PAIS partial androgen insensitivity syndrome

AIS androgen insensitivity syndrome

CAIS complete androgen insensitivity syndrome

DBD DNA-binding domain

DSD disorders of sexual development

kb kilobases

LBD C-terminal ligand-binding domain 
LH Luteinizing hormone

Declaration:

\section{Declarations}

Acknowledgements

Not applicable.

Funding

No funding was obtained for this study.

Availability of data and materials

All data generated or analyzed during this study are included in this published article.

Authors' contributions

PJL and JFX collected the data and they reviewed the literature, they write the paper together. JHL and WC

made substantial contribution to conception and design and made analysis and interpretation of data, they performed the surgery together. All authors read and approved the final manuscript. Each author participated adequately in the work to take public responsibility for appropriate portions of the content and agreed to be accountable for all aspects of the work.

Authors' contributions

PJL and JFX collected the data and they reviewed the literature, they write the paper together. JHL and WC made substantial contribution to conception and design and made analysis and interpretation of data, they performed the surgery together. All authors read and approved the final manuscript. Each author participated adequately in the work to take public responsibility for appropriate portions of the content and agreed to be accountable for all aspects of the work.

Ethics approval and consent to participate

Not applicable.

Consent for publication

Consent for publication has been obtained from the patient. A copy of written consent is available.

Competing interests 
The authors declare that they have no competing interests.

Publisher's Note

Springer Nature remains neutral with regard to jurisdictional claims in published maps and institutional affiliations.

\section{References}

1.Boehmer, A. L., Brinkmann, O., Bruggenwirth, H., van Assendelft, C., Otten, B. J., Verleun-Mooijman, M. C., ... Drop, S. L. (2001). Genotype versus phenotype in families with androgen insensitivity syndrome. $J$ Clin Endocrinol Metab, 86(9), 4151-4160. doi:10.1210/jcem.86.9.7825

2.Danilovic, D. L., Correa, P. H., Costa, E. M., Melo, K. F., Mendonca, B. B., \& Arnhold, I. J. (2007). Height and bone mineral density in androgen insensitivity syndrome with mutations in the androgen receptor gene. Osteoporos Int, 18(3), 369-374. doi:10.1007/s00198-006-0243-6

3.Doehnert, U., Bertelloni, S., Werner, R., Dati, E., \& Hiort, O. (2015). Characteristic features of reproductive hormone profiles in late adolescent and adult females with complete androgen insensitivity syndrome. Sex Dev, 9(2), 69-74. doi:10.1159/000371464

4.Edelsztein, N. Y., Grinspon, R. P., Schteingart, H. F., \& Rey, R. A. (2016). Anti-Mullerian hormone as a marker of steroid and gonadotropin action in the testis of children and adolescents with disorders of the gonadal axis. Int J Pediatr Endocrinol, 2016, 20. doi:10.1186/s13633-016-0038-2

5.Han, T. S., Goswami, D., Trikudanathan, S., Creighton, S. M., \& Conway, G. S. (2008). Comparison of bone mineral density and body proportions between women with complete androgen insensitivity syndrome and women with gonadal dysgenesis. Eur J Endocrinol, 159(2), 179-185. doi:10.1530/EJE-080166

6.Hughes, I. A., Davies, J. D., Bunch, T. I., Pasterski, V., Mastroyannopoulou, K., \& MacDougall, J. (2012). Androgen insensitivity syndrome. The Lancet, 380(9851), 1419-1428. doi:10.1016/s0140-6736(12)600713

7.Ismail-Pratt, I. S., Bikoo, M., Liao, L. M., Conway, G. S., \& Creighton, S. M. (2007). Normalization of the vagina by dilator treatment alone in Complete Androgen Insensitivity Syndrome and Mayer-RokitanskyKuster-Hauser Syndrome. Hum Reprod, 22(7), 2020-2024. doi:10.1093/humrep/dem074

8.Konrade, I., Zavorikina, J., Fridvalde, A., Rots, D., Kalere, I., Strumfa, I., . . Gailite, L. (2018). Novel Variant of the Androgen Receptor Gene in a Patient With Complete Androgen Insensitivity Syndrome and Polyorchidism. Front Endocrinol (Lausanne), 9, 795. doi:10.3389/fendo.2018.00795

9.Lahlou, N., Bouvattier, C., Linglart, A., Rodrigue, D., \& Teinturier, C. (2009). [The role of gonadal peptides in clinical investigation]. Ann Biol Clin (Paris), 67(3), 283-292. doi:10.1684/abc.2009.0329 
10.Liu, A. X., Shi, H. Y., Cai, Z. J., Liu, A., Zhang, D., Huang, H. F., \& Jin, H. M. (2014). Increased risk of gonadal malignancy and prophylactic gonadectomy: a study of 102 phenotypic female patients with $Y$ chromosome or Y-derived sequences. Hum Reprod, 29(7), 1413-1419. doi:10.1093/humrep/deu109

11.Liu, S., Wang, Z., Jiang, J., OuYang, H., Wei, S., Liang, J., . . Xie, X. (2019). Severe forms of complete androgen insensitivity syndrome caused by a p.Q65X novel mutation in androgen receptor: Clinical manifestations, imaging findings and molecular genetics. Steroids, 144, 47-51.

doi:10.1016/j.steroids.2019.02.007

12.Lubahn, D. B., Joseph, D. R., Sullivan, P. M., Willard, H. F., French, F. S., \& Wilson, E. M. (1988). Cloning of human androgen receptor complementary DNA and localization to the X chromosome. Science, 240(4850), 327-330.

13.Maciejewska-Jeske, M., Rojewska-Madziala, P., Broda, K., Drabek, K., Szeliga, A., Czyzyk, A., . . Kurpisz, M. (2018). New mutation causing androgen insensitivity syndrome - a case report and review of literature. Gynecol Endocrinol, 1-4. doi:10.1080/09513590.2018.1529160

14.Mongan, N. P., Tadokoro-Cuccaro, R., Bunch, T., \& Hughes, I. A. (2015). Androgen insensitivity syndrome. Best Pract Res Clin Endocrinol Metab, 29(4), 569-580. doi:10.1016/j.beem.2015.04.005

15.Morris, J. M. (1953). The syndrome of testicular feminization in male pseudohermaphrodites. Am J Obstet Gynecol, 65(6), 1192-1211.

16.Quigley, C. A., De Bellis, A., Marschke, K. B., el-Awady, M. K., Wilson, E. M., \& French, F. S. (1995). Androgen receptor defects: historical, clinical, and molecular perspectives. Endocr Rev, 16(3), 271-321. doi:10.1210/edrv-16-3-271

17.Silva, J. M., Batista, R. L., De Santi Rodrigues, A., Nishi, M. Y., Costa, E. M. F., Domenice, S., . . Mendonca, B. B. (2018). Androgen receptor mRNA analysis from whole blood: a low-cost strategy for detection of androgen receptor gene splicing defects. Clin Genet, 94(5), 489-490. doi:10.1111/cge.13437

18.Touzon, M. S., Garrido, N. P., Marino, R., Ramirez, P., Costanzo, M., Guercio, G., . . Belgorosky, A. (2019). Androgen Insensitivity Syndrome: Clinical Phenotype and Molecular Analysis in a Single Tertiary Center Cohort. J Clin Res Pediatr Endocrinol, 11(1), 24-33. doi:10.4274/jcrpe.galenos.2018.2018.0185

19.Wang, S., Xu, H., An, W., Zhu, D., \& Li, D. (2016). Mutational analysis of the androgen receptor gene in two Chinese families with complete androgen insensitivity syndrome. Exp Ther Med, 11(6), 2277-2283. doi:10.3892/etm.2016.3234

20.Wiener, J. S., Teague, J. L., Roth, D. R., Gonzales, E. T., Jr., \& Lamb, D. J. (1997). Molecular biology and function of the androgen receptor in genital development. $J$ Urol, 157(4), 1377-1386.

21.Yang, P., Liu, X., Gao, J., Qu, S., \& Zhang, M. (2018). Complete androgen insensitivity syndrome in a young woman with metabolic disorder and diabetes: A case report. Medicine (Baltimore), 97(33), e11353. 


\section{Table 1}

Due to technical limitations, table 1 is only available as a download in the supplemental files section.

\section{Figures}

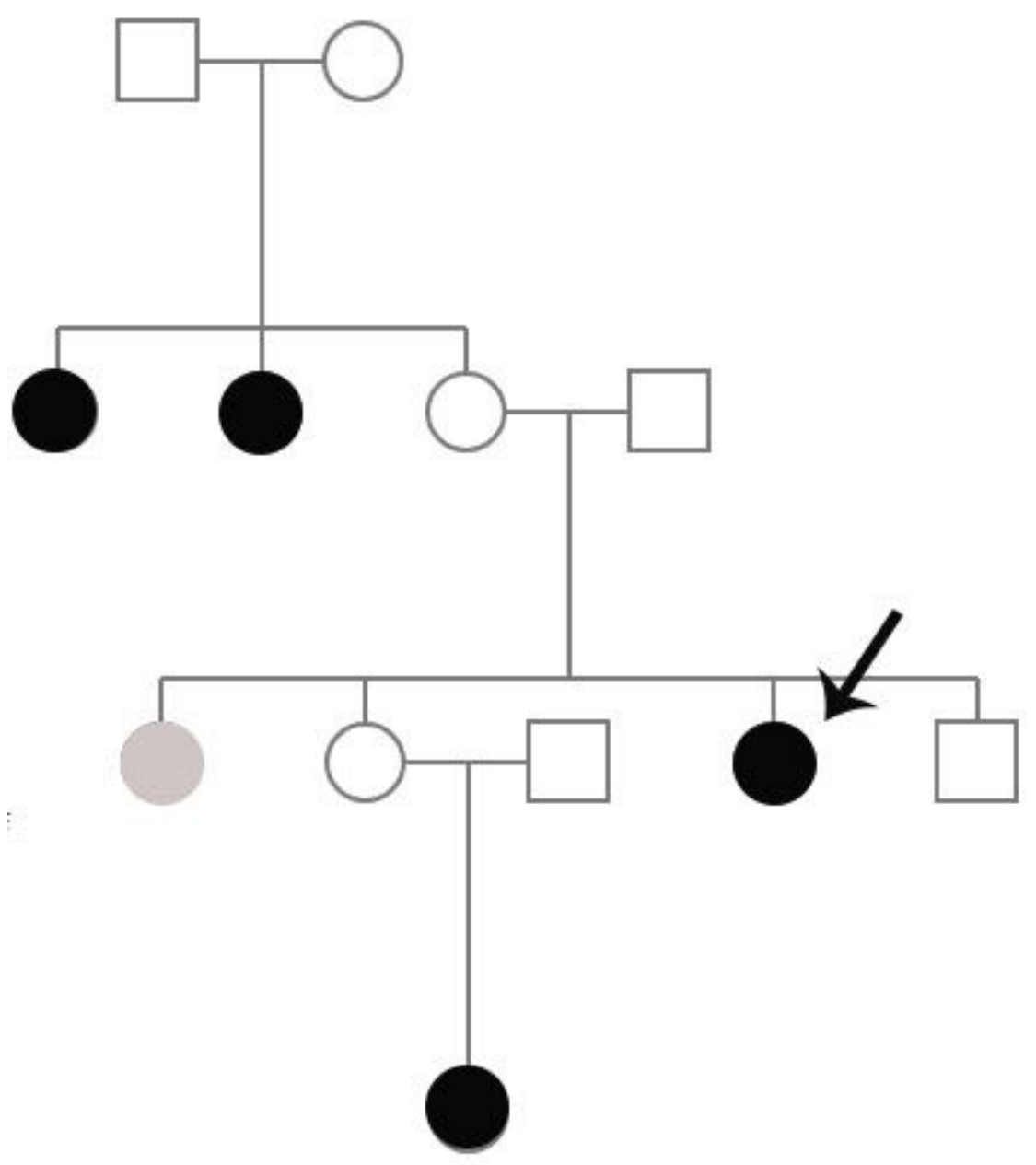

\section{Figure 1}

Patient's pedigree. Notes:Black circles indicate CAIS $46 \mathrm{XY}$ individuals, empty circles indicate normal females, empty squares indicate normal males, and grey circles indicate an infertile female. The black circle with the arrow represents the patient reported here. 

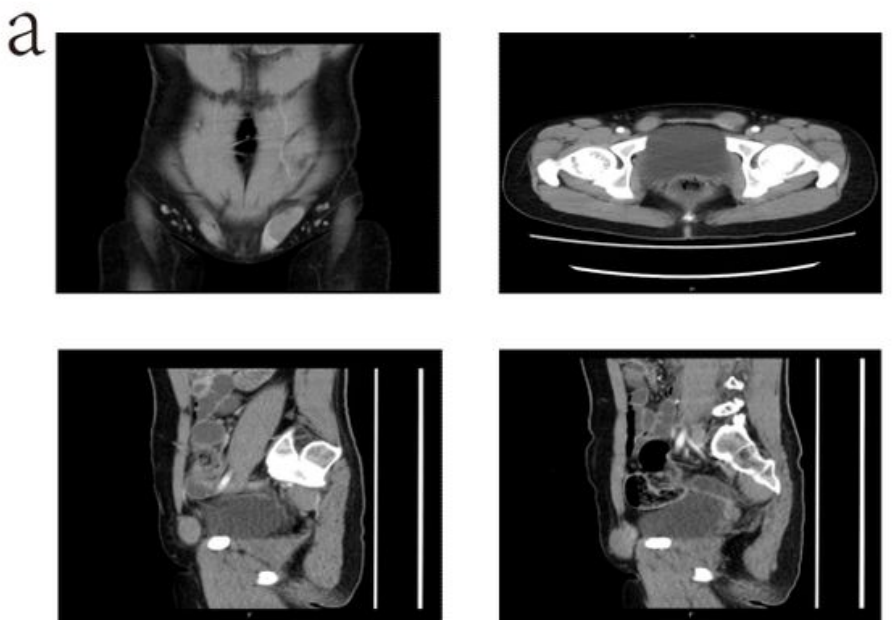

$\mathrm{b}$

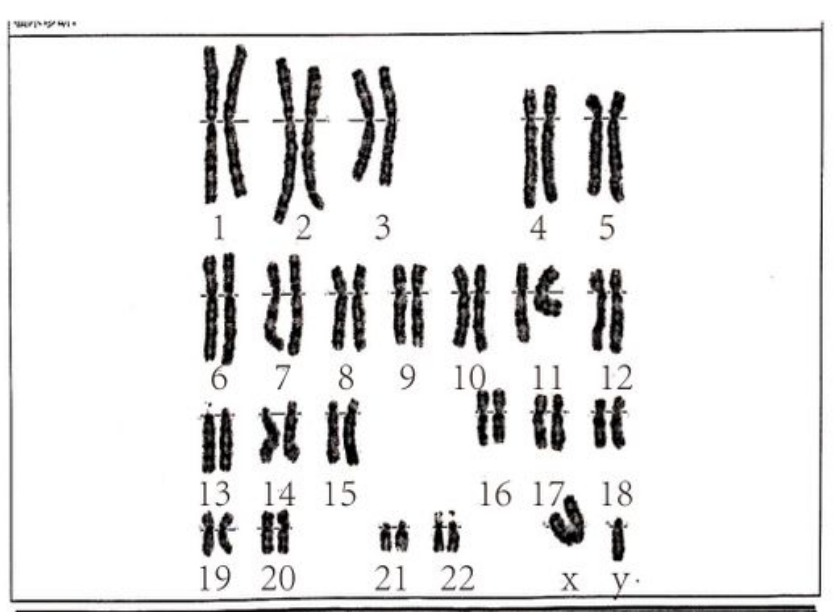

Figure 2

(a) Pre-operative CT image. (b) Patient karyotype.
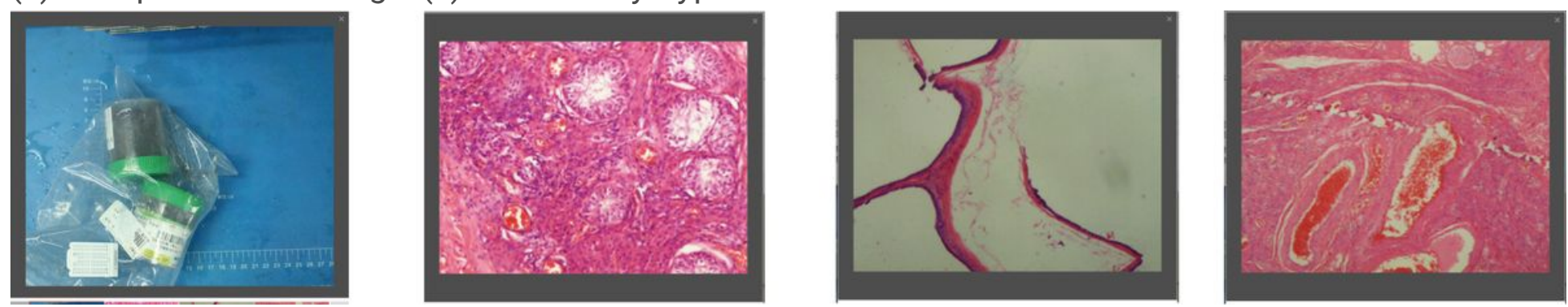

Figure 3

Pathological specimens confirming the presence of bilateral testes.
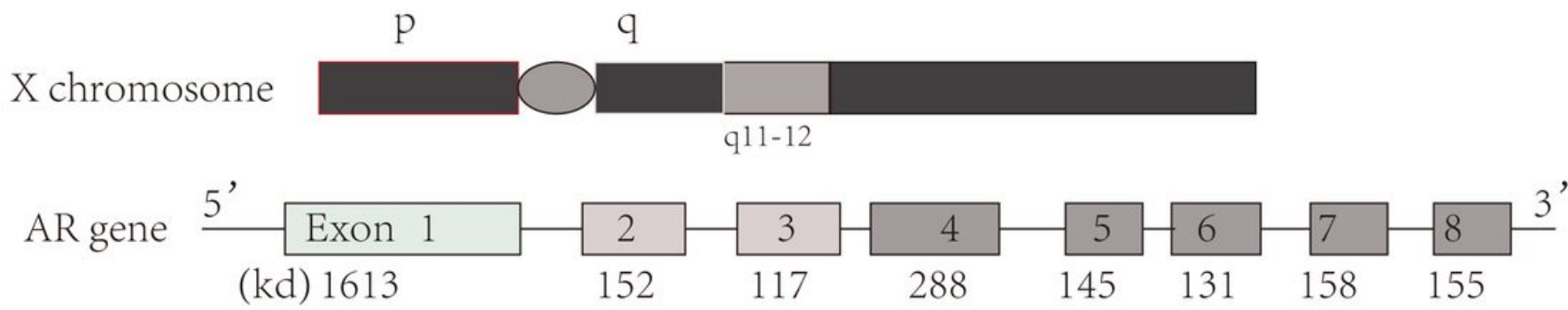

DNA Binding

AR protein

Hinge Ligand Binding

\section{Figure 4}

The structure of the AR gene and AR protein. 


\section{Supplementary Files}

This is a list of supplementary files associated with this preprint. Click to download.

- CAREchecklistEnglish.pdf

- Table1.xlsx 